\title{
Breakpoint characterization of a novel large intragenic deletion of MUTYH detected in a MAP patient: Case report
}

\author{
Giovana T Torrezan ${ }^{1}$, Felipe CC da Silva ${ }^{1}$, Ana CV Krepischi ${ }^{1,2}$, Érika MM Santos', Fábio de O Ferreira ${ }^{3}$, \\ Benedito M Rossi ${ }^{4}$ and Dirce M Carraro ${ }^{1,2^{*}}$
}

\begin{abstract}
Background: MUTYH-associated polyposis (MAP) is a recessive, hereditary, colorectal cancer-predisposing syndrome caused by biallelic mutations in the MUTYH gene. Most MUTYH pathogenic variants are missense mutations, and until recently no gross genomic deletions had been described.

Case Presentation: We have identified a large deletion in the MUTYH gene: a $>4.2 \mathrm{~kb}$ deletion encompassing exons 4-16. This is the second description of this rearrangement, which has been recently described as the first large deletion in this gene. The clinically suspected MAP patient was homozygous for this mutation and presented with no amplification products for 14 exons of MUTYH on initial screening. Deletion breakpoints were refined to base pair level through array comparative genomic hybridization $(\mathrm{aCGH})$ analysis followed by sequencing. The identified breakpoints were located within intron 3 and 146 bp downstream of the $3^{\prime}$ end of the gene, with the presence of an AluJr element adjacent to the distal breakpoint. The presence of a $2 \mathrm{bp}$ insertion at the junction suggests the involvement of the non-homologous end joining (NHEJ) repair mechanism, possibly facilitated by rearrangement-promoting elements. Examination of the MUTYH locus revealed a high Alu density that may make this region prone to rearrangements.
\end{abstract}

Conclusion: Large deletions are a possible mechanism for loss of function of the MUTYH gene, and investigation of such mutations may be important in identifying causative mutations in MAP patients.

\section{Background}

MUTYH-associated polyposis (MAP) (MIM\#608456), a recessive inherited syndrome characterized by colorectal adenomatous polyposis and a high risk of colorectal cancer, is a disorder caused by biallelic pathogenic germline variants in the human mutY homologue (MUTYH) gene [1]. MUTYH spans $11.2 \mathrm{~kb}$ on chromosome 1p34.1 [2] and encodes a DNA glycosylase that plays a key role in base excision repair (BER) of 8-oxoG: A mismatches by removing the mismatched adenine [3]. The oxidation product 8 -oxoG is the most stable product of oxidative DNA damage [4], which can lead to G: $\mathrm{C}$ to $\mathrm{T}$ :A transversions if not repaired ${ }^{5}$. Tumorigenesis

\footnotetext{
* Correspondence: dirce.carraro@accamargo.org.br

'International Center of Research and Training (CIPE), A. C. Camargo Hospital, São Paulo, SP, Brazil

Full list of author information is available at the end of the article
}

in MAP patients is thought to be initiated by somatic G: $\mathrm{C} \rightarrow \mathrm{T}$ :A transversions in KRAS and/or APC [5].

The clinical manifestations of MAP resemble familial adenomatous polyposis (FAP; MIM\#175100), which is caused by autosomal dominantly inherited pathogenic variants in the $A P C$ gene. Most biallelic MUTYH mutation carriers have between ten and several hundred polyps, usually with later onset compared to FAP patients [1,6]. Also, a number of MAP patients with CRC and no polyps have been reported [5]. Mutations in $M U T Y H$ account for approximately $40 \%$ of patients with 10-100 colorectal adenomas (attenuated FAP patients) and positive familial history, a proportion slightly higher than that of $A P C$ mutations in these patients (30\%) [7].

Nearly 300 different sequence variants have been identified so far in this gene (MUTYH Leiden Open Variation Database; http://chromium.liacs.nl/LOVD2/

\section{() Biomed Central}


colon_cancer/home.php?select_db=MUTYH). In contrast to pathogenic $A P C$ variants, which mostly result in a truncated or absent protein, most pathogenic MUTYH variants are missense variants and only a minority consists of splice site and truncating variants [2] The two hotspot mutations p.Tyr179Cys (exon 7) and p. Gly396Asp (exon 13) are prevalent in populations of European origin, probably due to a founder effect, and account for approximately $80 \%$ of all reported mutant alleles $[5,8]$. In the Brazilian population, a recently published paper on patients with clinical phenotypes of MAP, FAP and Lynch syndrome identified 4/60 (6.6\%) patients with these two hotspot mutations in a biallelic state [9]. Until recently, no gross genomic deletions or duplications had been described in this gene in any population.

Here, we report a case study in which we have characterized a large MUTYH deletion in a MAP patient. During the composition of this manuscript, an independent study performed by a French group identified this same rearrangement in one of their polyposis patients [10]. We have refined the breakpoint of this $>4.2 \mathrm{~kb}$ deletion to the base pair level. Based on the analysis of the sequences at breakpoints, we suggest a possible mechanism of origin for this alteration. Presence of this deletion was also analyzed in familial colorectal patients and a control group.

\section{Case Presentation}

A Brazilian female patient (FAP15) from the Hereditary Colorectal Cancer Registry of Hospital AC Camargo (São Paulo, Brazil), who was clinically suspected for MAP, was screened for mutations in the MUTYH gene by direct sequencing. The age at onset of the attenuated polyposis (approximately 40 polyps) was 42 years and of the rectal cancer was 44 years. No extracolonic manifestations were observed in this patient. Family history was accessed through personal report. The patient stated that she had unaffected deceased parents, four unscreened siblings (without colonoscopy) and one affected sister from whom biological material was unavailable due to residence distance (Figure 1). The affected sister presented with attenuated polyposis at the age of 44 years. The proband had a Caucasian ancestry, since her great-grandparents were Portuguese.

In addition, the presence of this MUTYH deletion was screened through PCR in other 183 Brazilian individuals: three $A P C / M U T Y H$-mutation negative and $18 \mathrm{APC} /$ $M U T Y H$-mutation positive polyposis patients (12 APC mutation carriers, 5 MUTYH biallelic and one $M U T Y H$ monoallelic mutation carriers); 51 clinically suspected Lynch syndrome patients (fulfilling Amsterdan II or Bethesda criteria), who were non-carriers of germline mutations in the mismatch repair (MMR) genes MLH1, MSH2, MSH6 and PMS2; and 111 healthy controls. Written informed consent was obtained from all patients and controls. This study was approved by the ethics committee of A. C. Camargo Hospital (approval number: 1169/08-B).

\section{Identification and characterization of the deletion}

We detected a homozygous deletion encompassing several exons of the MUTYH gene in this MAP patient. Genomic DNA was obtained from blood using the Puregene Genomic DNA Isolation Kit (Gentra Systems, USA) according to manufacturer's instructions.

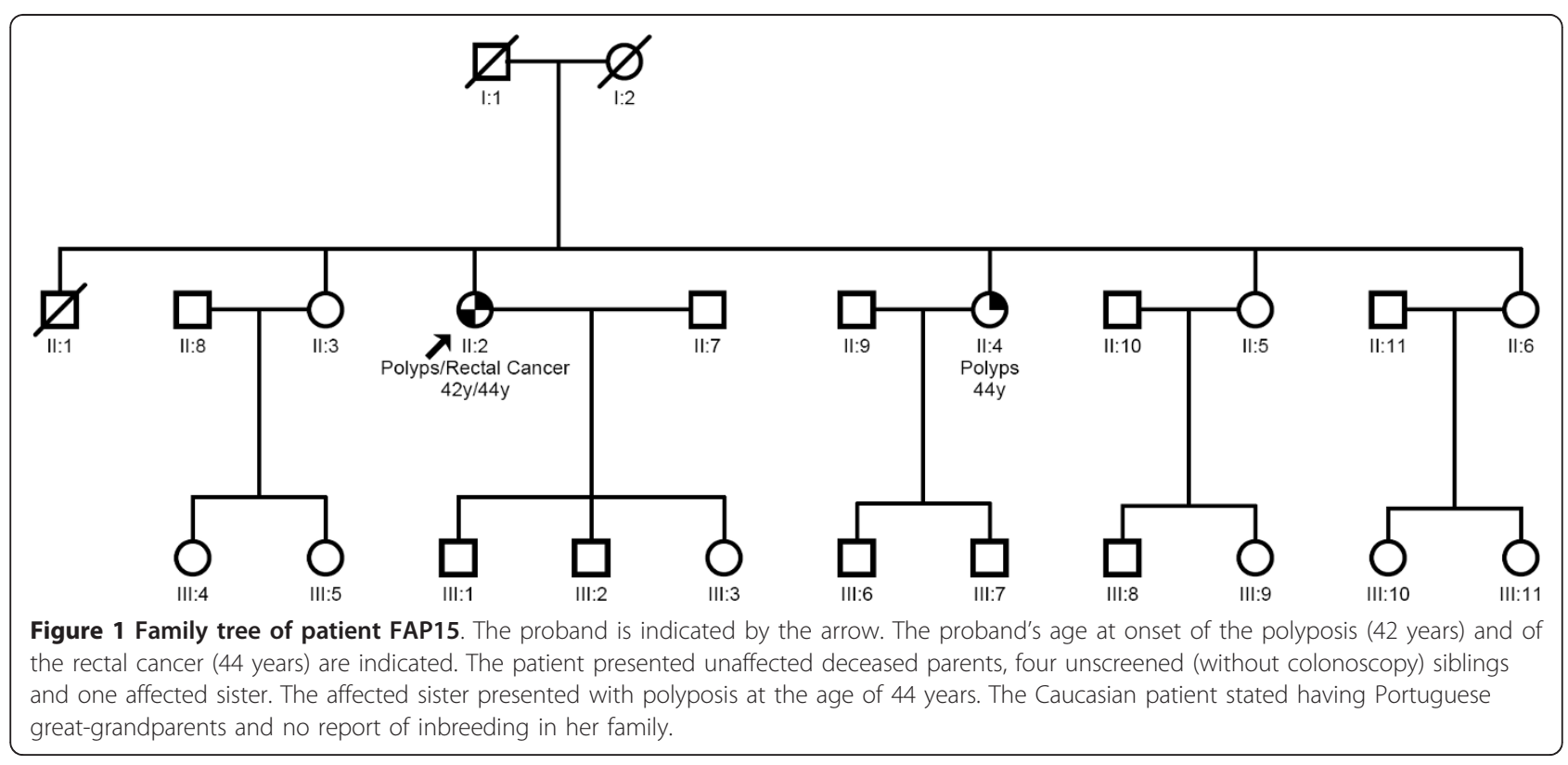


Eleven primer pairs were designed to amplify all 16 exons of MUTYH gene (NM_001128425.1), including intron-exon boundaries. Primers used for these analyses and PCR conditions are available upon request. Unexpected results were observed when performing standard PCR for MUTYH mutation screening on this patient; exons 3-16 could not be amplified (data not shown). As a positive control for the reaction, multiplex PCR in the presence of primers for control genes (GAPDH intron 7; HPRT1 exon 3) was performed for each MUTYH exon and confirmed the absence of genomic template for this gene. The results of multiplex PCR for the patient and a control DNA are shown in Figure 2A.
With the purpose of elucidating the extent of the deletion, comparative genomic hybridization based on microarrays $(\mathrm{aCGH})$ was performed. Briefly, samples were labeled with Cy3- and Cy5-dCTPs by random priming. Experiments were performed in duplicate using a $180 \mathrm{~K}$ whole-genome platform (OGT Technologies). Purification, hybridization, and washing were performed as recommended by the manufacturer. Data extraction was conducted using the Feature Extraction software (Agilent Technologies). We applied the Genomic Workbench software (Agilent Technologies) for identifying the constitutive genomic imbalances using the statistical algorithm ADM-2, with a sensitivity threshold of 6.7 , a threshold $\log _{2}$ ratio of 0.4 or 1.1 for duplication or high

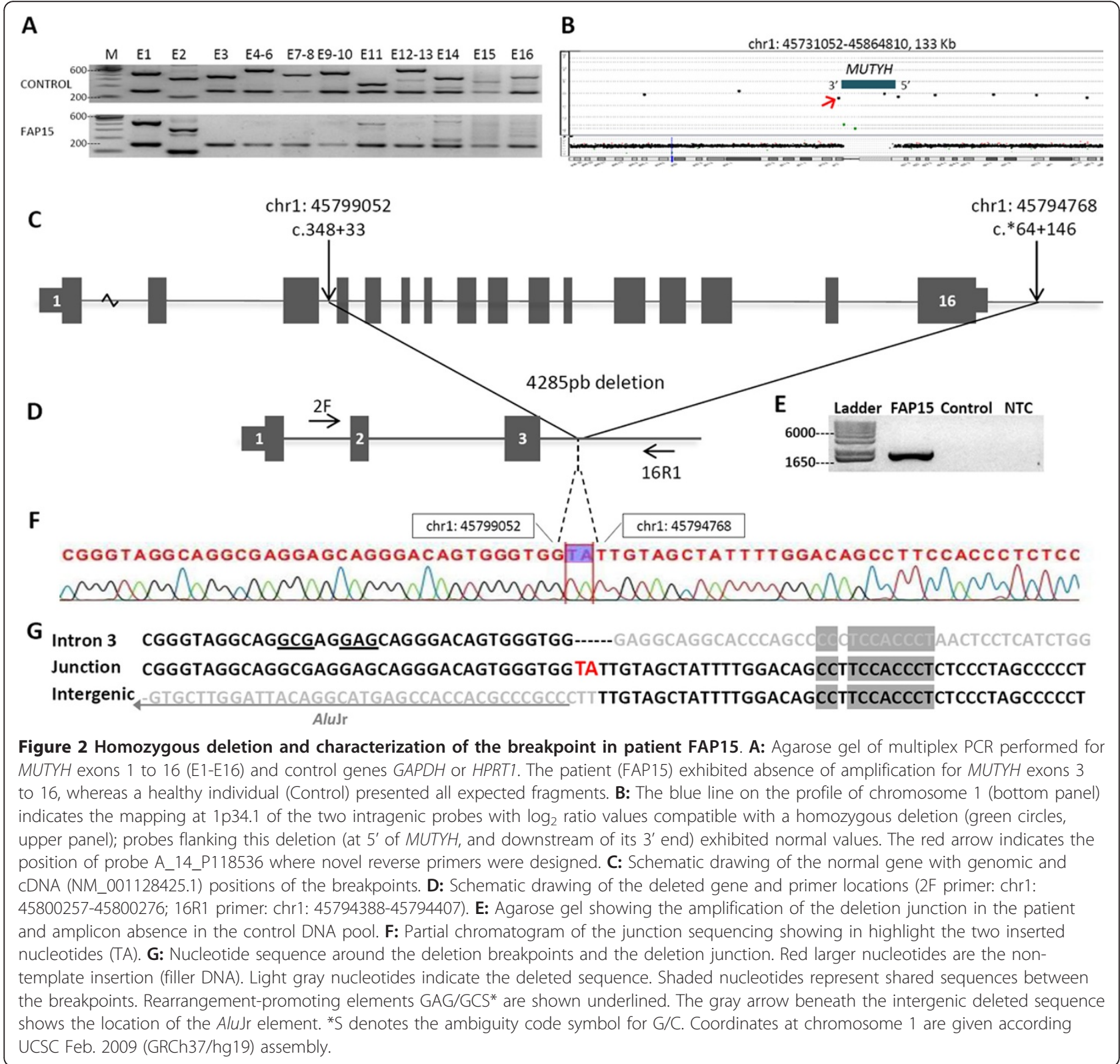


copy number gain, and -0.4 and -1.1 for deletion and homozygous loss, respectively.

Data analysis detected two sequences mapped within the $M U T Y H$ gene that exhibited $\log _{2}$ ratio values compatible with a homozygous deletion (oligoprobes A_14_P107667, mapped at chr1:45794902-45794961, and A_14_P122926, at chr1:45797594-45797640; coordinates given according to UCSC Feb. 2009 (GRCh37/ hg19) assembly) (Figure 2B). Oligoprobes flanking the deletion at the 5' end of MUTYH gene sequence and downstream of the 3' end had $\log _{2}$ ratios values consistent with two copies (A_14_P122926-chr1:4580434845804405, and A_14_P118536-chr1:45793780-45793830) (Figure 2B). Using an exon 2 forward primer (5'GGTGGATGAGAGGGAGATAG-3') and reverse primers designed on the position of the A_14_P118536 undeleted probe and 600 bp upstream (primers 16R2: 5'-CTTCAGGTCTTCACCAAGTCC-3' and 16R1: 5'CTTCTCCTGTGCTTCCTCTC-3', respectively), we successfully amplified the junction fragments for this deletion. After confirming that the primer 16R1 was located at an undeleted region and as it was closest to the breakpoint, further analyses were performed only with this primer. The PCR reaction of the control DNA pool failed to amplify any detectable PCR product (theoretically $5889 \mathrm{bp}$ in length), whereas PCR products of $\approx$ 1600 bp were detected using genomic DNA from the patient (Figure 2E). Briefly, the PCR conditions consisted of $25 \mathrm{ng}$ of genomic DNA, $0.3 \mu \mathrm{mol}$ of each primer and 1X Platinum ${ }^{\circledR}$ PCR SuperMix High Fidelity (Invitrogen) in a $20 \mathrm{uL}$ reaction. Cycling conditions entailed a preincubation at $95^{\circ} \mathrm{C}$ for 2 minutes followed by 35 cycles of denaturation at $95^{\circ} \mathrm{C}$ for 20 seconds, annealing at $62^{\circ} \mathrm{C}$ and extension at $72^{\circ} \mathrm{C}$ for 2 minutes. Direct sequencing of the junction fragments identified the exact breakpoints (genomic position: chr1: g.45,794,768_45,799,052del4285insTA, cDNA position: c. $348+33$ * $64+146$ del4285insTA), the precise size of the deletion interval $(4,285 \mathrm{~kb})$ and the affected exons (416) (Figure $2 \mathrm{C}$ and 2D). Genomic positions were confirmed using MUTALYZER 2.0 software. Previously, exon 3 appeared to be deleted in the PCR analysis because the breakpoint is located upstream of the reverse primer site. No region of the adjacent $H P D L$ gene is deleted downstream of the 3' end of MUTYH.

As the patient investigated in this study presented a homozygous mutation and reported no inbreeding in her family, we examined the presence of this deletion among 111 healthy controls, 21 polyposis patients and 51 patients with familial CRC negative for mutations on MMR genes. The junction fragment could not be amplified from the DNA of any other patient or control (data not shown). One possible explanation for the homozygous occurrence of the deletion in this patient, without consanguineous parents, is the inheritance of two alleles of a founder mutation in the population. The proband's great-grandparents were Portuguese, therefore she had Caucasian ancestry. In this sense, very recently this same deletion was found in a European MAP patient in compound heterozygosity with the common MUTYH Caucasian mutation p.Gly396Asp [10]. The description of the same rearrangement in patients from different geographic regions is a very exciting discovery and additional studies to uncover the origin and frequency of this mutation would be of great value. Another potential explanation for the homozygosity is the occurrence of isodisomy, a type of uniparental disomy that results in two identical segments from one parental homologue and can occur due to a recombination event in the zygote, though the existence of an affected sibling does not support this hypothesis.

Analysis of the junction sequence revealed several important features, including an insertion of $2 \mathrm{bp}$ of non-template DNA (Figure 2F), several recombination motifs such as GCG and GAS [11] and the presence of an $A l u \mathrm{Jr}$ element located 2 bases upstream of the distal breakpoint (Figure 2G). No repetitive element is present at the upstream breakpoint. Examination of the MUTYH locus using the Repeat-Masker software http:// www.repeatmasker.org/ revealed an Alu density of $22.2 \%$ for an 11,800 kb region (chr1:45,794,343-45,806,142), which includes the entire gene (11,229 bp), and $571 \mathrm{bp}$ downstream, which encompasses the distal breakpoint characterized in this study (Figure 3).

This study is particularly important from both a clinical and research perspective because we have identified the first large intragenic deletion in $M U T Y H:$ a $4.285 \mathrm{~kb}$ homozygous deletion in a MAP patient (c. [348+33_"64 +146del4285insTA]; [348+33_"64+146del4285insTA]). This mutation was submitted to the MUTYH LOVD Mutation Database and has been publicly available since May 12th: http://chromium.liacs.nl/LOVD2/colon_cancer/variants.php?select_db $=$ MUTYH\&action $=$ view\&view $=1012041 \% 2 \mathrm{C} 0002450 \% 2 \mathrm{C} 10$. The patient presented a homozygous deletion encompassing exons 4 to 16 detected and mapped through PCR, aCGH and sequencing. Breakpoints were sequenced and analysis of the junction sequence allowed us to postulate that classical nonhomologous end joining (NHEJ) is the most likely mechanism responsible for the deletion, as a 2-bp non-template insertion sequence is observed at the breakpoint junction $[12,13]$. This repair process involves the double strand breakage of DNA followed by end joining in the absence of extensive sequence homology, and is associated with small insertions at the junction sites [14] and with very short stretches of sequence identity ( $a$ few bp) between the two ends of the breakpoint junctions [15]. Analysis of breakpoints 


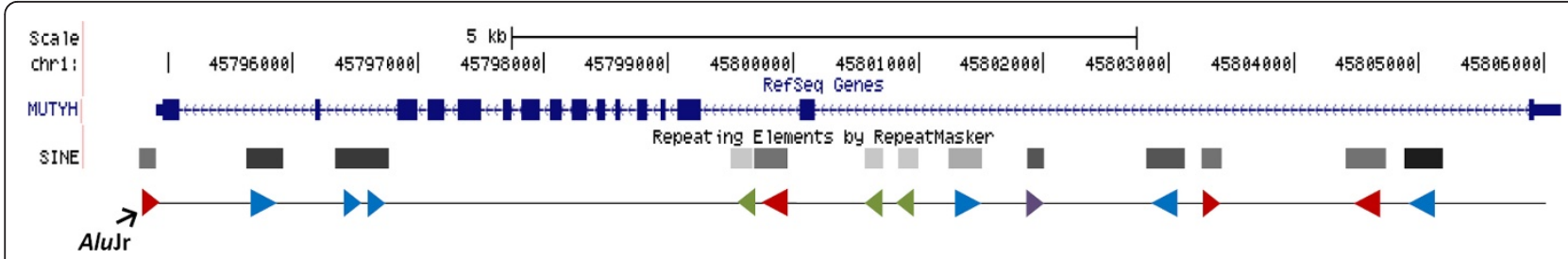

Figure 3 Short interspersed nucleotide element (SINE) content of the MUTYH genomic region (chr1:45794343-45806142) (data from UCSC database and RepeatMasker). A region of $11.8 \mathrm{~kb}$ is shown, extending 571 bp downstream of the MUTYH gene. Vertical bars in the genomic sequence indicate exons. The direction of the arrowheads denotes the orientation of the SINE repeat elements and each family is represented by a different color (Red: AluJ, Blue: AluS, Green: MIR, Purple: FLAM_C). The black arrow indicates the AluJr element involved in the distal breakpoint; no repetitive element is present on the proximal breakpoint.

surrounding sequences revealed the presence of an AluJr adjacent to the distal breakpoint and the existence of recombination/deletion promoting motifs [11] such as GAG and GCS trinucleotides. These motifs are known DNA polymerase pause-site core elements [16] and might have facilitated deletion.

In silico analysis of the Alu content in the MUTYH gene region revealed a high ratio of $A l u$ sequences per kb, with Alu elements occurring once in every $1.8 \mathrm{~kb}$ (22.2\%) when compared with the average of the human genome where Alu elements account for about $10 \%$ and occur once every $3 \mathrm{~kb}$ [17]. A recent study of more than 20 genes found evidence that a high content of transposable elements causes increased frequency of gene disruption by gross deletions in human disease [18]. Additionally, the local enrichment of Alus has been observed in regions with recurrent $A l u$-mediated rearrangements, e.g., the $V H L$ locus in von Hippel-Lindau disease patients [19], and in genes implicated in colorectal cancer-predisposing disorders such as Lynch and Peutz-Jeghers syndromes (EPCAM-MSH2 [20] and STK11 [21], respectively). However, not every Alu-rich gene is prone to this type of deletion formation. Examples include the thymidine kinase or b-tubulin genes [20,22]. In the MUTYH gene, a recent study has shown that a polymorphic AluY insertion in intron 15 when in a homozygous state, leads to a 2.15 fold increase in the levels of 8-oxoG in leukocyte DNA and is associated with type 2 diabetes mellitus [23]; however, this insertion has not yet been studied in the context of colorectal cancer.

\section{Conclusions}

Currently, there is no information on the percentage of defects in the MUTYH gene caused by deletions/duplications of complete exons, and screening for this type of mutation is not a common practice as it is with the $A P C$ gene. Our finding highlights the importance of performing screening methods, such as qPCR, MLPA or long-range PCR, for large MUTYH deletions in polyposis patients. Furthermore, it remains to be addressed whether the high density of Alu elements in this gene can cause an elevated frequency of $A l u$-mediated deletions and rearrangements. Nevertheless, the evidence shown here suggests that deletions could represent an important mechanism of loss of function in the MUTYH gene.

\section{Consent}

Written informed consent was obtained from all patients and controls for publication of this case report and any accompanying images. Copies of the written consents are available for review by the Editor-in-Chief of this journal.

\section{Acknowledgements and Funding}

The authors acknowledge the patients for their collaboration, the Nucleic Acid Bank of A. C. Camargo Hospital for sample processing and Bianca C. G. Lisboa for guidance in establishing the sequencing protocols. This work was supported by National Institute of Science and Technology in Oncogenomics (INCITO)-FAPESP: 2008/57887-9.

\section{Author details}

${ }^{1}$ International Center of Research and Training (CIPE), A. C. Camargo Hospital, São Paulo, SP, Brazil. ${ }^{2}$ National Institute of Science and Technology in Oncogenomics (INCITO), São Paulo, SP, Brazil. ${ }^{3}$ Colorectal Tumors Department, A. C. Camargo Hospital, São Paulo, SP, Brazil. ${ }^{4}$ Barretos Cancer Hospital-Pio XII Foundation, Barretos, São Paulo, Brazil.

\section{Authors' contributions}

GTT designed and performed the molecular genetic studies and drafted the manuscript. FCCS participated in the experimental design and revised the manuscript critically. ACVK carried out the aCGH analysis and revised the manuscript critically. EMMS participated in the clinical data acquirement and analysis. FOF conceived the study, and participated in its coordination. BMR conceived of the study, and participated in its design. DMC participated in its experimental design and coordination and helped to draft the manuscript. All authors read and approved the final manuscript.

\section{Competing interests}

The authors declare that they have no competing interests.

Received: 6 July 2011 Accepted: 30 September 2011

Published: 30 September 2011

\section{References}

1. Al-Tassan N, Chmiel NH, Maynard J, Fleming N, Livingston AL, Williams GT, Hodges AK, Davies DR, David SS, Sampson JR, Cheadle JP: Inherited variants of MYH associated with somatic G:C- $>$ T:A mutations in colorectal tumors. Nat Genet 2002, 30(2):227-32. 
2. Out AA, Tops CMJ, Nielsen ÃM, Weiss MM, Minderhout IJHMV, Fokkema IFAC, Buisine M-Pierre, Claes K, Colas C, Fodde R, Fostira F, Franken PF, Gaustadnes M, Heinimann K, Hodgson SV, Hogervorst FBL, Holinski-feder E, Lagerstedt-robinson K, Olschwang S, Ouweland AMWVD, Redeker EJW, Scott RJ, Vankeirsbilck B, Grønlund RV, Wijnen JT, Wikman FP, Aretz S, Sampson JR, Devilee P, Dunnen JTD, Hes FJ: Leiden Open Variation Database of the MUTYH Gene Human Mutation. Hum Mutat 2010, 31(11):1205-1215.

3. Nghiem Y, Cabrera M, Cupples CG, Miller JH: The mutY gene: a mutator locus in Escherichia coli that generates G.C--T.A transversions. PNAS 1988, 85(8):2709-13.

4. Sampson JR, Jones S, Dolwani S, Cheadle JP: MutYH (MYH) and colorectal cancer. Biochem Soc Trans 2005, 33(4):679-683.

5. Nielsen M, Morreau H, Vasen HFA, Hes FJ: MUTYH-associated polyposis (MAP). Crit Rev Oncol Hematol 2010, 1-16.

6. Sampson JR, Dolwani S, Jones S, Eccles D, Ellis A, Evans DG, Frayling I, Jordan S, Maher ER, Mak T, Maynard J, Pigatto F, Shaw J, Cheadle JP: Autosomal recessive colorectal adenomatous polyposis due to inherited mutations of MYH. Lancet 2003, 362(9377):39-41.

7. Filipe $B$, Baltazar $C$, Albuquerque $C$, Fragoso S, Lage P, Vitoriano I, Mão de Ferro S, Claro I, Rodrigues P, Fidalgo P, Chaves P, Cravo M, Nobre Leitão C: APC or MUTYH mutations account for the majority of clinically wellcharacterized families with FAP and AFAP phenotype and patients with more than 30 adenomas. Clin Genet 2009, 76:242-255.

8. Aretz S, Hes FJ: Clinical utility gene card for: MUTYH-associated polyposis (MAP), autosomal recessive colorectal adenomatous polyposis. Eur $J$ Hum Genet 2010, 2-4

9. Pitroski CE, Cossio SL, Koehler-Santos P, Graudenz M, Prolla JC, Ashtonprolla P: Frequency of the common germline MUTYH mutations p.G396D and p.Y179C in patients diagnosed with colorectal cancer in Southern Brazil. Int J Colorectal Dis 2011, 3:1-16.

10. Rouleau E, Zattara H, Lefol C, Noguchi T, Briaux A, Buecher B, Bourdon V, Sobol H, Lidereau R, Olschwang S: First large rearrangement in the MUTYH gene and attenuated familial adenomatous polyposis syndrome. Clin Genet 2011, 80:301-303.

11. Abeysinghe SS, Chuzhanova N, Krawczak M, Ball EV, Cooper DN Translocation and gross deletion breakpoints in human inherited disease and cancer I: Nucleotide composition and recombinationassociated motifs. Hum Mutat 2003, 22(3):229-44.

12. Korbel JO, Urban AE, Affourtit JP, Godwin B, Grubert F, Simons JF, Kim PM Palejev D, Carriero NJ, Du L, Taillon BE, Chen Z, Tanzer A, Saunders ACE, Chi J, Yang F, Carter NP, Hurles ME, Weissman SM, Harkins TT, Gerstein MB, Egholm M, Snyder M: Paired-End Mapping Reveals Extensive Structural Variation in the Human Genome. Science 2007, 420(318):420-426.

13. Perry GH, Ben-dor A, Tsalenko A, Sampas N, Rodriguez-revenga L, Tran CW, Scheffer A, Steinfeld I, Tsang P, Yamada NA, Park HS, Kim J-il, Seo J-sun, Yakhini Z, Laderman S, Bruhn L, Lee C: The Fine-Scale and Complex Architecture of Human Copy-Number Variation. Am J Hum Genet 2008, 82:685-695.

14. Linardopoulou EV, Williams EM, Fan Y, Friedman C, Young JM, Trask BJ: Human subtelomeres are hot spots of interchromosomal recombination and segmental duplication. Nature 2005, 437:94-100.

15. Chan CY, Kiechle M, Manivasakam P, Schiestl RH: lonizing radiation and restriction enzymes induce microhomology-mediated illegitimate recombination in Saccharomyces cerevisiae. Nuc Ac Res 2007, 35(15):5051-9.

16. Weaver DT, DePamphilis ML: Specific Sequences in Native DNA that Arrest Synthesis by DNA Polymerase a. Biol Chem 1982, 257(4):2075-2086.

17. Lander ES, Linton LM, Birren B, Nusbaum C, Zody MC, Baldwin J, Devon K, Dewar K, Doyle M, FitzHugh W, Funke R, Gage D, Harris K, Heaford A, Howland J, Kann L, Lehoczky J, LeVine R, McEwan P, McKernan K, Meldrim J, Mesirov JP, Miranda C, Morris W, Naylor J, Raymond C, Rosetti M, Santos R, Sheridan A, Sougnez C, et al: Initial sequencing and analysis of the human genome. Nature 2001, 409(6822):860-921.

18. Zelm MCV, Geertsema C, Nieuwenhuis N, Ridder DD, Conley ME, Schiff C, Tezcan I, Bernatowska E, Hartwig NG, Sanders EAM, Litzman J, Kondratenko I, Dongen JJMV, Burg MVD: Gross Deletions Involving IGHM, BTK, or Artemis: A Model for Genomic Lesions Mediated by Transposable Elements. J Hum Genet 2008, , 82: 320-332.

19. Franke G, Bausch B, Hoffmann MM, Cybulla M, Wilhelm C, Kohlhase J, Scherer G, Neumann HPH: Alu-Alu recombination underlies the vast majority of large VHL germline deletions: Molecular characterization and genotype-phenotype correlations in VHL patients. Hum Mutat 2009, 30(5):776-86.

20. Kuiper RP, Vissers LELM, Venkatachalam R, Bodmer D, Hoenselaar E, Goossens M, Haufe A, Kamping E, Niessen RC, Hogervorst FBL, Gille JJP, Redeker B, Tops CMJ, van Gijn ME, van den Ouweland AMW, Rahner N, Steinke V, Kahl P, Holinski-Feder E, Morak M, Kloor M, Stemmler S, Betz B, Hutter P, Bunyan DJ, Syngal S, Culver JO, Graham T, Chan TL, Nagtegaal ID, et al: Recurrence and variability of germline EPCAM deletions in Lynch syndrome. Hum Mutat 2011, 32(4):407-14.

21. Resta N, Giorda R, Bagnulo R, Beri S, Della Mina E, Stella A, Piglionica M, Susca FC, Guanti G, Zuffardi O, Ciccone R: Breakpoint determination of 15 large deletions in Peutz-Jeghers subjects. Hum Genet 2010, 128(4):373-82.

22. Batzer MA, Deininger PL: Alu repeats and human genomic diversity. Nat Rev Genet 2002, 3:370-379.

23. Chen H, Sun C, Guo W, Meng R, Du H, Qi Q, Gu X, Li L, Zhang K, Zhu D, Wang Y: AluYb8 insertion in the MUTYH gene is related to increased 8OHdG in genomic DNA and could be a risk factor for type 2 diabetes in a Chinese population. Mol Cell Endocrinol 2011, 332:301-305.

\section{Pre-publication history}

The pre-publication history for this paper can be accessed here: http://www.biomedcentral.com/1471-2350/12/128/prepub

\section{doi:10.1186/1471-2350-12-128}

Cite this article as: Torrezan et al:: Breakpoint characterization of a novel large intragenic deletion of MUTYH detected in a MAP patient: Case report. BMC Medical Genetics 2011 12:128.

\section{Submit your next manuscript to BioMed Central and take full advantage of:}

- Convenient online submission

- Thorough peer review

- No space constraints or color figure charges

- Immediate publication on acceptance

- Inclusion in PubMed, CAS, Scopus and Google Scholar

- Research which is freely available for redistribution 